Dietary exposure to dioxin-like compounds in three age groups: Results from the Flemish environment and health study

Peer-reviewed author version

Bilau, Maaike; Matthys, Christophe; Baeyens, Willy; BRUCKERS, Liesbeth; De Backer, Guy; Den Hond, Elly; Keune, Hans; Koppen, Gudrun; Nelen, Vera;

Schoeters, Greet; Van Larebeke, Nicolas; Willems, Jan L. \& De Henauw, Stefaan (2008) Dietary exposure to dioxin-like compounds in three age groups: Results from the Flemish environment and health study. In: CHEMOSPHERE, 70(4). p. 584-592.

DOI: $10.1016 /$ j.chemosphere.2007.07.008

Handle: http://hdl.handle.net/1942/8017 


\title{
Dietary exposure to dioxin-like compounds in three age groups: Results from the Flemish environment and health study
}

\author{
Maaike Bilau ${ }^{\mathrm{a}, *}$, Christophe Matthys ${ }^{\mathrm{a}}$, Willy Baeyens ${ }^{\mathrm{b}}$, Liesbeth Bruckers ${ }^{\mathrm{c}}$, \\ Guy De Backer a, Elly Den Hond ${ }^{\mathrm{d}}$, Hans Keune ${ }^{\mathrm{e}}$, Gudrun Koppen ${ }^{\mathrm{d}}$, Vera Nelen ${ }^{\mathrm{f}}$, \\ Greet Schoeters ${ }^{d}$, Nicolas Van Larebeke ${ }^{\mathrm{g}}$, Jan L. Willems ${ }^{\mathrm{a}}$, Stefaan De Henauw ${ }^{\mathrm{a}}$, \\ On behalf of the Flemish Center of Expertise for Environment and Health \\ ${ }^{a}$ Department of Public Health, Ghent University, UZ 2 Blok A, De Pintelaan 185, B-9000 Ghent, Belgium \\ ${ }^{\mathrm{b}}$ Department of Analytical and Environmental Chemistry, Free University of Brussels, Pleinlaan 2, B-1050 Brussels, Belgium \\ ${ }^{\mathrm{c}}$ Center for Statistics, University Hasselt, Agoralaan 1, Building D, B-3590 Diepenbeek, Belgium \\ ${ }^{\mathrm{d}}$ Flemish Institute of Technological Research (VITO), Environmental toxicology, Boeretang 200, B-2400 Mol, Belgium \\ ${ }^{\mathrm{e}}$ Department of Sociology, Antwerp University, Sint Jacobstraat 2, B-2000 Antwerp, Belgium \\ ${ }^{\mathrm{f}}$ Provincial Institute of Hygiene (PIH), Kronenburgstraat 40, B-2000 Antwerp, Belgium \\ ${ }^{\mathrm{g}}$ Studycentre of Carcinogenesis and Primary Prevention of Cancer, Ghent University, UZ 3K3, De Pintelaan 185, B-9000 Ghent, Belgium
}

Received 2 April 2007; received in revised form 2 July 2007; accepted 5 July 2007

Available online 27 August 2007

\begin{abstract}
Lipophilic contaminants are present in the environment and bioaccumulate in the food chain. Therefore, their intake via animal fat of various sources was assessed for three age groups of the Flemish population, participating in a large biomonitoring program of the Flemish government. In total, 1636 adolescents (14-15 years), 1186 mothers (18-44 years), and 1586 adults (50-65 years) participated in the study and completed a semi quantitative food frequency questionnaire. Individual consumption data were combined, via a so-called simple distribution approach, with recent data on polychlorinated dibenzo- $p$-dioxins/furans and dioxin-like polychlorinated biphenyls, measured via the chemical-activated luciferase gene expression (CALUX) bio-assay in food items available on the Flemish market.

The median (95th percentile) estimated intakes of dioxin-like contaminants were 2.24 (4.61), 2.09 (4.26), and 1.74 (3.53) pg CALUXTEQ $\mathrm{kg}^{-1}$ bw d ${ }^{-1}$ for, respectively adolescents, mothers and adults. These data are in the same range as those found in other European studies. The CALUX-TEQ results of respectively $59.8 \%, 53.7 \%$ and $36.2 \%$ of the adolescent, mother and adult population exceed the tolerable weekly intake (TWI) of $14 \mathrm{pg}$ WHO-TEQ $\mathrm{kg}^{-1} \mathrm{bw} \mathrm{w}^{-1}$, as derived by the Scientific Committee on Food [Scientific Committee on Food, 2001. Opinion of the Scientific Committee on Food on the Risk Assessment of Dioxins and Dioxin-like PCBs in Food, CS/ CNTM/DIOXIN/20 final Brussels, Belgium].

The main contributors of dioxin-like substances are fish and seafood (25-43\% of the total intake), added fats (22-25\% of the total intake) and dairy products (17-20\% of the total intake).
\end{abstract}

(c) 2007 Elsevier Ltd. All rights reserved.

Keywords: Dietary intake; PCDD/Fs; Dioxin-like PCBs; Flanders

Abbreviations: 2,3,7,8-TCDD, 2,3,7,8-tetrachlorodibenzo-p-dioxin; AhR, arylhydrocarbon receptor; BMI, body mass index; bw, body weight; CALUX, chemical-activated luciferase gene expression; dl-PCBs, dioxin-like polychlorinated biphenyls; FFQ, food frequency questionnaire; GC-HRMS, gas chromatography-high resolution mass spectrometry; LOAEL, lowest observed adverse effect level; NOAEL, no observed adverse effect level; PCBs, polychlorinated biphenyls; PCDDs, polychlorinated dibenzo-p-dioxins; PCDFs, polychlorinated dibenzofurans; TDI, tolerable daily intake; TEF, toxic equivalence factor; TEQ, toxic equivalents; TWI, tolerable weekly intake.

Corresponding author. Tel.: +329332 24 23; fax: +3293324994.

E-mail address: maaikebilau@yahoo.com (M. Bilau). 


\section{Introduction}

A number of environmental contaminants are considered to bear substantial risks for human health. Some of these contaminants predominantly reach the human body through the diet-despite often low concentrations in individual food items and become relevant on the basis of the chronic exposure and the tendency of these contaminants to accumulate in the body.

Dioxin-like contaminants (such as polychlorinated dibenzo- $p$-dioxins (PCDDs), polychlorinated dibenzofurans (PCDFs) and dioxin-like polychlorinated biphenyls (dlPCBs)) enter the food chain via deposition and further bioaccumulation, due to their lipophilic character. Their presence in the environment is unintentional for PCDDs and PCDFs, whereas PCBs were extensively produced by industry since 1930 and used worldwide until they were banned in the seventies (WHO, 1989, 1993). Dioxin-like compounds produce multi-organ toxicity and some are classified as possible carcinogens. The International Agency for Research on Cancer (IARC) has concluded that 2,3,7,8-tetrachlorodibenzo- $p$-dioxin $(2,3,7,8$-TCDD) is carcinogenic in humans (Group 1) (IARC, 1987). Polychlorinated biphenyls are classified as probably carcinogenic to humans (Group 2A) (IARC, 1997). A toxic equivalence factor (TEF) has been assigned to seven PCDDs, 10 PCDFs and 12 dioxin-like PCBs in order to compare their toxicity with 2,3,7,8-TCDD (Van den Berg et al., 1998). These TEF values have been revised recently (Van den Berg et al., 2006).

Since, concentrations in food items (especially food items containing fat of animal origin) and absorption after ingestion are high (Arisawa et al., 2005), dietary intake is assumed to be the most important source of dioxin-like contaminants for humans. Dietary intake is estimated to account for at least $90 \%$ of total exposure, with products of animal origin making the greatest contribution to this exposure (Fries, 1995; Liem et al., 2000; Parzefall, 2002).

In the aftermath of an important food safety incident in Belgium (1999), caused by an accidental spilling of industrial PCBs in the human food chain, detailed intake estimations of dioxin-like substances were published (Focant et al., 2002; Vrijens et al., 2002). These intake estimations were based on dietary intake data from a relatively small sample of adolescents from one particular region in Belgium (city of Ghent), collected in 1997 (Matthys et al., 2003), and on contaminant data available at that moment. Since then, dioxin concentration data in food items available on the Belgian market are routinely measured by the Belgian Agency for the Safety of the Food Chain (http:// www.favv.be).

In view of the importance of continued monitoring of the risks posed by these contaminants, it was deemed useful to revise the dietary intake assessment and to generate updated distributions of dietary exposure to $\mathrm{PCDD} / \mathrm{Fs}$ and dl-PCBs in the Belgian population, using more recent consumption and contamination data and based on a pop- ulation sample from a broader geographical area. In this paper, exposure assessment estimations are presented for three distinct subgroups of the Flemish population. In addition, the contribution of different food groups to the overall exposure is described and discussed.

\section{Material and methods}

The consumption data for this intake assessment were gathered via a biomonitoring program, executed by the Flemish Center of Expertise for Environment and Health financed and steered by the Flemish Community (http:// www.milieu-en-gezondheid.be). This biomonitoring program ran from 2002 till 2006 and covered different study areas within Flanders-the Dutch speaking, northern half of Belgium. Three age groups have been studied: mothers and their newborn child, adolescents and adults. Participants were sampled from eight areas in Flanders with different types of pollution pressure: two urban areas (Ghent and Antwerp), four areas with different types of industry (harbour, non-ferrous smelter, chemical industry, waste incinerator) and two rural areas.

The biomonitoring study was approved by the Ethical Committee of the University of Antwerp, Belgium.

\subsection{Participant recruitment}

The inclusion criteria for the individuals of all three age groups were: (1) living for at least 5 years in the respective area, (2) giving informed consent, and (3) being able to complete questionnaires in Dutch. Adolescents had to be born in 1988 or 1989 (and hence 14 or 15 years old at the time of the study) and had to be in the third year of secondary school. Adults had to be between 50 and 65 years old at the time of the study. For the mothers, no age range was defined a priori, but was of course determined by the typical reproductive age range in a Western country.

Mothers and their newborns were enrolled via 25 maternity hospitals between October 2002 and December 2003. These maternity hospitals were selected by stratified sampling. Midwives of the maternity homes did a first selection on the basis of the address of the women. Nurses visited the selected women in the maternity to check for eligibility of participation.

Adolescents were enrolled via 42 schools between October 2003 and July 2004. In every trimester, secondary schools were selected by stratified sampling. The selected schools provided lists of pupils of the third year. From these lists, pupils with the corresponding date of birth and residing in one of the areas under study were selected. Both the pupil and the parents had to give their informed consent before the pupil was allowed to take part in the study.

For the sampling of adults, municipalities were selected at random within the different study areas. The selected municipalities provided addresses of individuals who fell in the correct age range. From September 2004 till June 
2005, individuals were selected via stratified sampling, based on 3 age groups (50-54, 55-59 and 60-65).

On the basis of a short questionnaire, sent to 6867 individuals, it could be determined whether people fulfilled the inclusion criteria. Partners who met the inclusion criteria, could also participate in the study. People who did not meet the inclusion criteria, were randomly replaced by individuals from the same age group and the same sex.

The selection of the maternities, schools and municipalities was done via stratified systematic weighted sampling. Stratification took place at the level of the eight study areas. Within a study area, each entity (maternity, school or municipality) had a chance to be included in the study proportional to its size (respectively, the number of deliveries on a yearly basis; the number of pupils with the correct age and the number of inhabitants aged 50-65 years). The systematic weighted procedure guaranteed that large entities are included with certainty in the study, but also a representation of the group of smaller entities is ensured.

\subsection{Measurements}

All participants completed an extensive questionnaire (self-administered), assessing information on lifestyle, dietary intake, use of tobacco and alcohol, residence history, education and occupation (if applicable). Body mass index (BMI) of the mothers was calculated, based on self-reported height and weight. For adolescents and adults, height and body weight were measured according to a standardized protocol (WHO, 1995). In case of the mothers, umbilical cord blood was taken after delivery, while adolescents and adults provided a non-fasting blood and urine sample. Since these samples were not used for this part of the study, the authors have chosen not to go into detail with regard to this.

Dietary intake was assessed via a semi-quantitative food frequency questionnaire (FFQ). This questionnaire was based on the Dutch ANI-questionnaire (van Dooren-Flipsen and van Klaveren, 1998) and adapted to Flemish dietary habits. The aim of this FFQ was to estimate the daily consumption of fat-containing food items, with a focus on animal fat. Food groups such as meat and meat products, fish and seafood, eggs and dairy products were extensively questioned, as well as added fats (e.g. baking and frying fat).

The FFQ consisted of 152 questions on frequency: "how often do you consume this food item/this food group?" with 7 response categories, ranging from "never or less than 1 day a month" to "6-7 days a week". The second part of each question consisted of an open-ended question on portion size: "how much do you consume of this food item/this food group on that day?". Extra questions $(N=27)$ on kind of product (e.g. what type of canned fish) or fat content (e.g. for milk, cheese, ...) were also included, if applicable.

Since FFQs are known to overestimate the intake of food items, especially when long questionnaires are used (Willett, 1994, 1998; Paalanen et al., 2006), a correction was done by dividing the questionnaire in so-called "main questions" and "subquestions". The main questions focussed on a food group (e.g. meat and meat products), while in the subquestions several food items of a food group (e.g. different types of meat) were listed. To correct for overestimation, which could occur due to the multitude of food items assessed in the subquestions, the frequency of consumption was determined by the answer on the main question. The subquestions were, however, necessary in order to know the contribution of consumption of the different food items within one food group because of their different fat content and origin. Also the average portion size consumed, can differ between different food items.

The participants were asked to estimate their intake based on dietary habits of the year before being pregnant (for mothers) or the year before completing this questionnaire (for adolescents and adults). For each individual, dietary intake of fat from each different fat origin is calculated on the basis of Dutch and Belgian food composition tables (NEVO, 2001; NUBEL, 2004), as well as recipe books (KVLV, 1999; KAV-Practische School, 2003) and in a limited number of cases also on the basis of information from food industry. As a result, fat intake could be subdivided according to the origin: beef, pork, sheep, horse, chicken, turkey, cereals, yoghurt, milk, eggs, cheese, cooking and frying fats, seafood (shrimps and mussels) and fish (lean fish, fatty fish, smoked fish and canned fish).

\subsection{Contaminant concentrations}

Levels of PCDD/Fs and dl-PCBs in food items, sampled between 2003 and 2006, were provided by the Belgian Federal Agency for the Safety of the Food Chain. Sampling of food items was performed along a prefixed sampling scheme, as suggested by the European Commission (2002). The chemical-activated luciferase gene expression (CALUX) assay was used to analyse the food items. The CALUX assay uses a recombinant cell line, which responds to PCDD/Fs and dioxin-like molecules with Ah receptor (AhR)-dependent induction of firefly luciferase in a dose related response. The methodology used is described elsewhere (Vanderperren et al., 2004).

Before 2004, CALUX measurements included PCDD/ Fs, but not dl-PCBs. The latter were removed from the extract by separation on a carbon column. Since 2004 dl-PCBs have been measured in the separated fraction. Therefore, the number of samples can be different for both analyses. The results are expressed as CALUX toxic equivalents (CALUX-TEQ) since calibration was carried out with 2,3,7,8-TCDD solutions.

In order to perform the intake assessment, individual food items were grouped into several food groups, based on fat content and fat origin (see Table 1). Groups were also chosen in view of the feasibility of combining the consumption with the contamination data. For each food group, a mean PCDD/F concentration and a mean dl-PCB concentration was calculated (Table 1). Other food groups, such as fruits and vegetables have also been analysed, but all samples of banana, pear, strawberry, apricot, current, kiwifruit, 
Table 1

Mean (standard deviation) PCDD/F and dl-PCB concentration for each food group

\begin{tabular}{|c|c|c|c|c|c|}
\hline Food group & Expressed in & $N$ & $\mathrm{PCDD} / \mathrm{Fs}$ & $N$ & dl-PCBs \\
\hline \multicolumn{6}{|c|}{ Meat and meat products } \\
\hline Chicken & pg CALUX-TEQ/g fat & 76 & $1.2(1.18)$ & 53 & $0.9(0.69)$ \\
\hline Turkey & pg CALUX-TEQ/g fat & 11 & $0.6(0.30)$ & 8 & $0.6(0.21)$ \\
\hline Pork & pg CALUX-TEQ/g fat & 45 & $0.7(2.01)$ & 36 & $0.6(0.23)$ \\
\hline Beef & pg CALUX-TEQ/g fat & 134 & $1.3(0.69)$ & 133 & $1.5(1.50)$ \\
\hline Sheep & pg CALUX-TEQ/g fat & 11 & $3.4(5.58)$ & 11 & $1.1(0.83)$ \\
\hline Horse & pg CALUX-TEQ/g fat & 13 & $5.6(4.10)$ & 8 & $4.9(3.26)$ \\
\hline \multicolumn{6}{|c|}{ Fish and seafood } \\
\hline Shrimps & pg CALUX-TEQ/g product & 16 & $2.0(0.67)$ & 15 & $2.2(1.35)$ \\
\hline Mussels & pg CALUX-TEQ/g product & 4 & $1.7(0.96)$ & 2 & $2.2(0.92)$ \\
\hline Lean fish ${ }^{\mathrm{a}}$ & pg CALUX-TEQ/g product & 97 & $0.8(0.68)$ & 95 & $0.9(0.85)$ \\
\hline Herring & pg CALUX-TEQ/g product & 15 & $1.4(0.39)$ & 15 & $2.1(1.56)$ \\
\hline Mackerel & pg CALUX-TEQ/g product & 2 & $1.0(0.64)$ & 2 & $1.0(0.75)$ \\
\hline Salmon & pg CALUX-TEQ/g product & 73 & $1.0(0.62)$ & 61 & $1.2(0.80)$ \\
\hline Eel & pg CALUX-TEQ/g product & 12 & $1.2(0.61)$ & 10 & $0.8(0.58)$ \\
\hline Smoked fish & pg CALUX-TEQ/g product & 30 & $0.8(0.38)$ & 30 & $1.2(0.83)$ \\
\hline Canned fish & pg CALUX-TEQ/g product & 27 & $0.5(0.22)$ & 38 & $0.8(0.64)$ \\
\hline \multicolumn{6}{|c|}{ Dairy products } \\
\hline Cheese & pg CALUX-TEQ/g fat & 47 & $1.4(0.78)$ & 36 & $1.1(0.55)$ \\
\hline Milk & pg CALUX-TEQ/g fat & 274 & $1.5(0.71)$ & 237 & $1.4(0.78)$ \\
\hline Yoghurt & pg CALUX-TEQ/g fat & 6 & $1.1(0.50)$ & 6 & $0.9(0.43)$ \\
\hline \multicolumn{6}{|c|}{ Other food groups } \\
\hline Cereals & pg CALUX-TEQ/g product & 4 & $0.3(0.17)$ & 2 & $0.6(0.02)$ \\
\hline Egg & pg CALUX-TEQ/g fat & 286 & $1.0(0.98)$ & 283 & $1.0(1.27)$ \\
\hline Added fats ${ }^{b}$ & pg CALUX-TEQ/g fat & 77 & $0.8(0.51)$ & 36 & $1.2(0.74)$ \\
\hline
\end{tabular}

${ }^{\text {a }}$ Lean fish: cod, plaice, ray, sole, Nile perch, whiting, anglerfish and turbot.

b Added fats: spreads, baking and frying fat.

peach, mango, cauliflower, asparagus, broccoli, leek, celery, tomato, Belgian endive, white cabbage and carrot did not contain levels above the limit of quantification. For apple and lettuce respectively 1 out of 30 and 2 out of 13 samples contained detectable values. Therefore these food items were not taken into account. For the other food groups non-detects were assumed to be half of the limit of quantification (medium bound value).

\subsection{Intake estimation}

To estimate the dietary intake of dioxin-like compounds, a simple distribution approach was used, combining a point estimate for contaminant concentration with the observed distribution of individual consumption data (Lambe, 2002). Non-parametric tests (Mann-Whitney $U$-test; $p<0.05$ ) were used to study the differences between males and females (SPSS ${ }^{\circledR}$ version 12.0). The contribution of different food groups is calculated as a population proportion (Krebs-Smith et al., 1989).

\section{Results}

\subsection{Response and participation rate}

The recruitment resulted in a sample of 1186 mothers and 1196 neonates. In total, 1172 mothers completed the FFQ adequately. From those meeting the criteria, only $2 \%$ refused to participate in this biomonitoring study. Of the women who did not participate in the study, almost half $(44 \%)$ did not meet the inclusion criteria. Other main reasons for non-participation were oblivion of the midwife $(30 \%)$ or difficulties during delivery $(17 \%)$.

Of all adolescents who received the invitation, $28.4 \% \mathrm{did}$ not respond, this might be due to the fact that they did not fulfill the inclusion criteria or because they were not interested. Among the pupils who did respond, $14.7 \%$ refused to participate. Among the pupils who were wiling to participate, $2.3 \%$ were excluded by the researchers because they did not reside in the area since 5 years, and for $1.9 \%$ participation was not complete (incomplete questionnaires or insufficient blood or urine). The recruitment resulted in 1636 adolescents who participated in the study and completed the FFQ adequately.

For adults, $47.5 \%(N=3263)$ of the contacted individuals replied: $5.3 \%$ of them did not meet the inclusion criteria, $24.7 \%$ refused to participate. From the people contacted by phone, $22.3 \%$ were not able to be present on the day of the survey. In total, 1586 adults ( $49 \%$ men) participated in the study and completed the FFQ adequately.

\subsection{Characteristics of the participants}

Table 2 shows the basic characteristics and dietary intake of the participants of the study.

There are statistical differences $(p<0.001)$ in daily consumption of meat and meat products, dairy products (milk, butter, cheese, yoghurt), eggs and total fat between adoles- 
Table 2

Characteristics and dietary intake of the participants, expressed as medians (P25-P75)

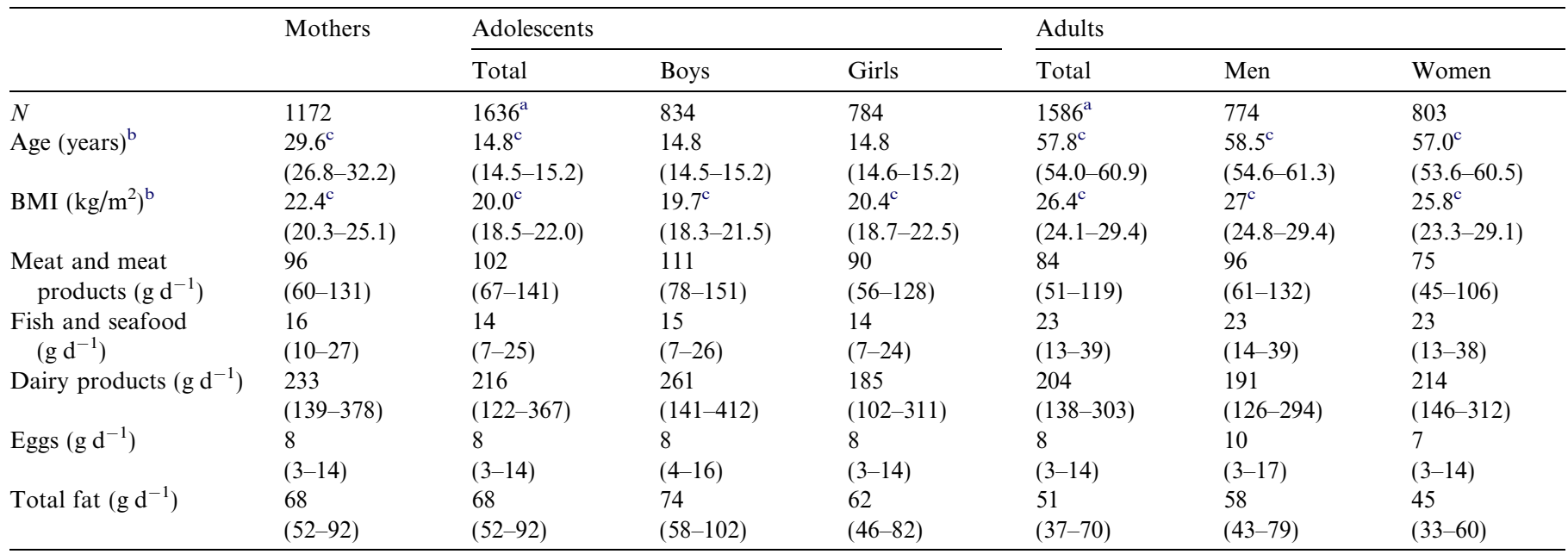

${ }^{\text {a }}$ The total number of adolescents (resp. adults), is not equal to the sum of boys and girls (resp. men and women), because for some adolescents (adults) gender was missing.

${ }^{\mathrm{b}}$ Age and BMI have a normal distribution. Therefore, the mean and the median do not differ significantly.

${ }^{\mathrm{c}}$ There were some missing data: age (mothers): 16 missing; BMI (mothers): 42 missing; age (adolescents): 18 missing; BMI (adolescents): 20 missing; BMI (boys): 1 missing; BMI (girls): 1 missing; age (adults): 8 missings; BMI (adults): 13 missing; age (men): 2 missings; BMI (men): 1 missing; BMI (women): 3 missing.

cent boys and girls. For adult men and women, similar statistical differences can be found, except for the consumption of dairy products.

The percentage of non-consumers shows relatively large variations for the different populations, at least for certain food groups. The percentage of non-consumers for fish \& seafood decreases with age: respectively, $6.3 \%, 4.4 \%$ and $2.5 \%$ of the adolescent, mother and adult population does not consume fish or seafood at all. The same trend can be seen for milk: going from $2.3 \%$ non-consumers for adolescents, over $1.5 \%$ for mothers towards $0.9 \%$ for the adult population. Around $1 \%$ of the total population is a nonconsumer of meat and meat products, while $12 \%$ never consumes eggs. It should be mentioned that eggs, used in preparations such as cake, quiches or sauces, are not taken into account for the calculation of the proportion of nonconsumers. However, for the actual intake estimation, they are taken into account.

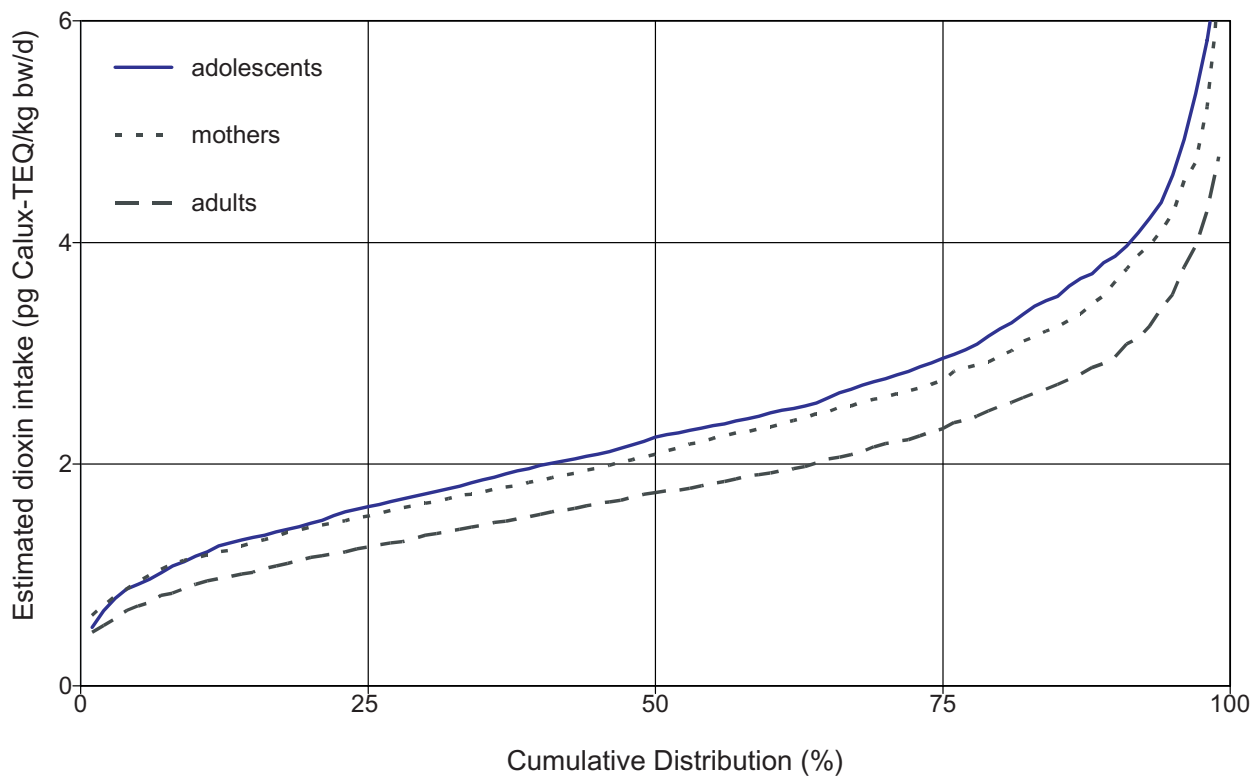

Fig. 1. Cumulative distribution of the estimated dietary intake of dioxin-like compounds (pg CALUX-TEQ $\mathrm{kg}^{-1} \mathrm{bw} \mathrm{d}^{-1}$ ) for three Flemish subpopulations. 


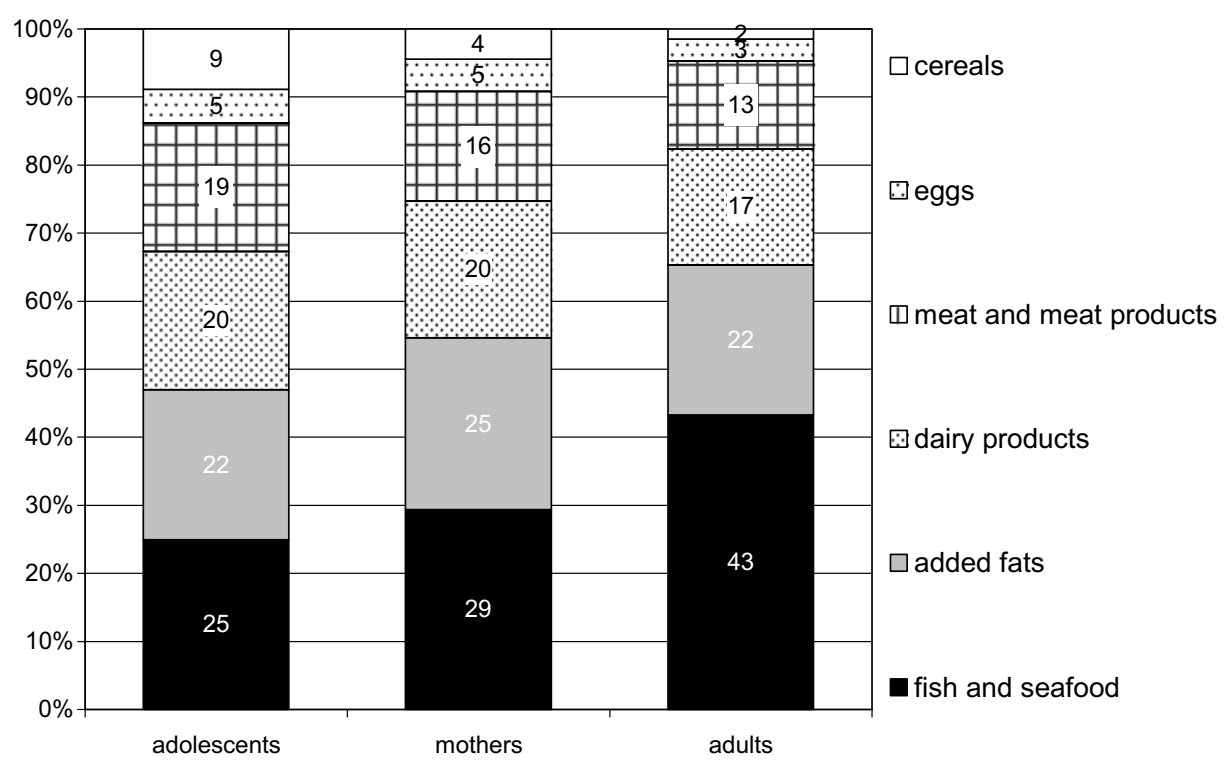

Fig. 2. Estimated average contribution of food groups (\%) to the intake of dioxin-like substances in three subgroups of the Flemish population.

\subsection{Intake estimation of dioxin-like substances}

The cumulative distribution functions of the estimated dietary intake of the sum of PCDD/Fs and dl-PCBs for the three Flemish subpopulations are presented in Fig. 1.

The median estimated intake for adolescents, mothers and adults is respectively 2.24, 2.09 and 1.74 pg CALUXTEQ $\mathrm{kg}^{-1} \mathrm{bw} \mathrm{d} \mathrm{d}^{-1}$. At the 95th percentile, the intake levels are respectively, $4.61,4.26$ and $3.53 \mathrm{pg}$ CALUXTEQ $\mathrm{kg}^{-1}$ bw d ${ }^{-1}$.

\subsection{Main contributors of dioxin-like substances via food}

The contribution of different food groups to the total of dioxin-like contaminants is presented in Fig. 2. Fish and seafood is the most important contributor to the total estimated intake of dioxin-like contaminants. The importance of this food group increases with age, while the importance of meat and meat products decreases with age.

\section{Discussion}

This study reports the estimated dietary intake of dioxin-like substances for three Flemish subpopulations: adolescents ( $N$ : 1636; age: $14-15$ years), mothers $(N$ : 1172; age: 18-44 years) and adults $(N$ : 1586; age: 50-65 years). These subpopulations are representative for the selected age-groups in the selected regions.

The estimated intakes of dioxin-like substances are decreasing with age, from a median of 2.24 to a median of $1.74 \mathrm{pg}$ CALUX-TEQ $\mathrm{kg}^{-1} \mathrm{bw} \mathrm{d}^{-1}$. The consumption of total fat is higher in the adolescent population than it is in the adult population, while the bodyweight of adolescents is lower than that of adults.

Intake estimations, based on contaminant levels measured as CALUX activity, exceed for respectively $59.8 \%$,
$53.7 \%$ and $36.2 \%$ of the adolescent, mother and adult population the tolerable weekly intake (TWI) of 14 pg WHOTEQ $\mathrm{kg}^{-1} \mathrm{bw} \mathrm{w}^{-1}$ (or 7 times the tolerable daily intake of $2 \mathrm{pg}$ WHO-TEQ $\mathrm{kg}^{-1}$ bw d ${ }^{-1}$ ), as derived by the European Commission (Scientific Committee on Food, 2001). The WHO consultation recommended a TDI for dioxins and dl-PCBs of 1-4 pg WHO-TEQ $\mathrm{kg}^{-1} \mathrm{bw} \mathrm{d}^{-1}$ based on the no-observed-adverse-effect-level (NOAEL) and the lowest-observed-adverse-effect-level (LOAEL) of those effects considered to be the most sensitive in experimental animals, namely endometriosis, developmental neurobehavioural effects, developmental reproductive effects and immunotoxicity (WHO-ECEH-IPCS, 2000). It was stressed that the upper range of the TDI of $4 \mathrm{pg}$ WHOTEQ $\mathrm{kg}^{-1}$ bw d $\mathrm{d}^{-1}$ should be considered a maximal tolerable intake on a provisional basis (WHO-ECEH-IPCS, 2000). This upper limit is exceeded by respectively $8.8 \%$, $6.7 \%$, and $2.8 \%$ of the adolescent, mother and adult population. However, these limits are set for the mixture of 7 PCDDs, 10 PCDFs and 12 PCBs which received a TEF value (Van den Berg et al., 1998). The CALUX results may include other compounds as well, which have resisted the clean-up procedure and which activate the AhR.

For Belgium, several intake assessments of dioxin-like substances are available, based on different food consumption and contamination data and using different methods to combine both in order to estimate the intake (Focant et al., 2002; Vrijens et al., 2002; De Bont et al., 2004; Baeyens et al., 2007). A detailed intake assessment was performed in the aftermath of the 1999 PCB incident by Vrijens et al. (2002). Applying a full probabilistic model, the intake of dioxin-like substances was estimated for adolescents (13-18 years), on the basis of a 7 day estimated food record and background contamination data, available at that moment. The result of such a model is a distribution for the population under study and can, therefore, be 
considered as more representative than the results of a deterministic procedure as applied in the other publications. The probabilistic intake assessment of dioxin-like substances, $\mathrm{PCDD} / \mathrm{Fs}$ and dl-PCBs, in adolescents provided an median value of $2.53 \mathrm{pg}$ WHO-TEQ $\mathrm{kg}^{-1}$ bw d $\mathrm{d}^{-1}$, varying from 1.15 (5th percentile) towards 6.52 (95th percentile). A median value which is only slightly higher than the intake calculated in this paper.

In other European countries, similar intake assessments were done for adult populations with mean estimated dietary intakes for dioxin-like contaminants $(\mathrm{PCDD} / \mathrm{Fs}$ and dioxin-like PCBs) of $1.5 \mathrm{pg}$ WHO-TEQ $\mathrm{kg}^{-1} \mathrm{bw} \mathrm{d}^{-1}$ in Finland (Kiviranta et al., 2004), $1.3 \mathrm{pg}$ WHO-TEQ $\mathrm{kg}^{-1}$ bw d ${ }^{-1}$ in Sweden (Darnerud et al., 2006) and $2.28 \mathrm{pg}$ WHO-TEQ $\mathrm{kg}^{-1} \mathrm{bw} \mathrm{d}^{-1}$ in Italy (Fattore et al., 2006). In the Netherlands, a recent dietary intake estimation resulted for the overall population in a median lifelong-averaged intake for dioxin-like substances of $1.2 \mathrm{pg}$ WHO-TEQ $\mathrm{kg}^{-1} \mathrm{bw} \mathrm{d}^{-1}$ (Baars et al., 2004). In Spain, the intake of $\mathrm{PCDD} / \mathrm{Fs}$ was estimated to be 1.36 and $0.91 \mathrm{pg}$ WHO-TEQ $\mathrm{kg}^{-1} \mathrm{bw} \mathrm{d}^{-1}$, respectively in Catalonia and Tarragona (Llobet et al., 2003; Bocio and Domingo, 2005). The results of the present study are within the range of these recent international surveys. Moreover, one should always be careful when comparing different studies. Indeed, methodological differences may play an important role in the final result. First of all, the age range of study populations is not always comparable. Second, food consumption data may be assessed using different methods (FFQ vs. dietary record vs. market basket data). Furthermore, contaminant levels may be quantified differently. Finally, differences in the mathematical procedures to assess the intake (deterministic vs. stochastic approach) may result in different intake estimates.

Dietary exposure assessments have their limitations; this also applies to our study.

First, the dietary intake is estimated on the basis of a semi-quantitative FFQ. The FFQ was chosen because this is the only affordable instrument that can be used to estimate long term intake for large numbers of respondents. This method, however, is known to overestimate the intake of food items, especially when long questionnaires are used (Paalanen et al., 2006; Willett, 1994, 1998).

Second, the data on contamination levels in food items were obtained through a monitoring program and were not part of this study. However, the sampling design has guaranteed random sampling of food items. This sampling is not region-specific but representative for the whole country. However, the authors could not influence what food items, nor how many samples of each food item were analysed. Also the method of analysis was not chosen by the authors themselves. The use of different methods to determine the levels of dioxin-like contaminants can result in differences: chemical analysis can measure various dioxinlike compounds quantitatively, while the CALUX assay integrates also biological effects of other toxicological substances activating the AhR (e.g. fluorinated and bromi- nated aromatic hydrocarbons). The CALUX response of the food extracts is calibrated against 2,3,7,8-TCDD. CALUX measures the toxicity of the food extract in comparison with dioxin toxicity in terms of activity of the arylhydrocarbon receptor (AhR). The results of the CALUX-bioassay have been compared to results obtained by chemical analysis, such as gas chromatography-high resolution mass spectrometry (GC-HRMS) (Van Overmeire et al., 2000; Vanderperren et al., 2004). Although bioassay results may show a higher variability in comparison to chemical analysis, results of both assays are well correlated (Schoeters et al., 2004). Extraction and sample clean-up have been shown to retain persistent halogenated compounds such as $\mathrm{PCDD} / \mathrm{Fs}$, while $\mathrm{PCBs}$ can be examined separately. In general, the results obtained by CALUX overestimate the levels of $\mathrm{PCDD} / \mathrm{Fs}$ as determined by chemical analysis (Vanderperren et al., 2004). Potential synergistic or antagonistic effects of dioxin-like compounds are thus taken into account (Schoeters et al., 2004; Van Overmeire et al., 2004; Joung et al., 2007).

Differences in contamination level between organic food items and food items from conventional farms were not taken into account. Almost $30 \%$ of the contaminant data on eggs were data on eggs from commercial, free range hens, while $15 \%$ were data on organic eggs. There are slight differences in contamination levels between those eggs and less contaminated eggs from conventional farms. Moreover, it is known that levels in eggs from free range hens, owned by private people, are even more elevated (Pussemier et al., 2004; Schoeters and Hoogenboom, 2006). No data were available on contamination levels of homeproduced eggs. Nevertheless, $20 \%$ of our study population consumes eggs from their own free range hens, circa $15 \%$ consumes eggs from a local farmer. Therefore, this might have influenced the estimated intake levels for eggs. A similar remark can be made for contaminant levels in fish: the levels of persistent organic pollutants differ significantly, depending on the season, the diet (wild or farmed), the age, the location,... (Scientific Advisory Committee on Nutrition, 2004).

Although fish is an important contributor to the overall intake of dioxin-like contaminants, it would, from a public health perspective, not be desirable to discourage people from including fish in their diet, without taking into account the fact that fish and seafood are important sources in the human diet of certain nutrients, such as long-chain $\omega-3$ poly-unsaturated fatty acids (Ruxton et al., 2005). However, the findings emphasise once more the importance of trying to control the levels of contaminants in fish and fish oils, e.g. by regulating the fish feed of farmed fish.

The second major contributor is the group of the added fats. Since the intake of saturated fats is known to be higher than recommended intakes in most developed countries (Willett, 2000; WHO, 2004; Matthys et al., 2006; Sioen et al., 2006), nutritional and food safety communications can be partly integrated into public health messages. The 
intake of dietary fats, especially saturated fatty acids, should be reduced, not only because of the role it plays in the development of chronic degenerative diseases, such as cardiovascular diseases and cancer, but also because it is an important contributor of dioxin-like substances.

\section{Conclusion}

This paper reported the estimated dietary intake of dioxin-like substances for three subgroups of the Belgian population (i.e. adolescents (14-15y), mothers (18-44 y) and adults $(50-65 \mathrm{y})$. A large part of the three study populations $(36-60 \%)$ appears to exceed the TWI of $14 \mathrm{pg}$ TEQ kg ${ }^{-1}$ bw week ${ }^{-1}$ (Scientific Committee on Food, 2001). Fish and seafood (25-43\% of the total intake) and added fats (22-25\% of the total intake) seem to be important contributors within the diet.

\section{Conflict of interest statements for authors}

There are no conflicts of interest for any of the authors.

\section{Acknowledgements}

The authors thank the dieticians Mrs. Mia Bellemans and Mrs. Mieke De Maeyer for their important contribution to the fieldwork and the data input. We also thank the Federal Agency for the Safety of the Food Chain (FAVV) for access to the analytical data. The intake assessment performed is solely the responsibility of the authors and does not engage the FAVV. The study was commissioned, financed and steered by the Ministry of the Flemish Community (Department of Science, Department of Public Health and Department of Environment), without any responsibility for the scientific content.

\section{References}

Arisawa, K., Takeda, H., Mikasa, H., 2005. Background exposure to PCDDs/PCDFs/PCBs and its potential health effects: a review of epidemiologic studies. J. Med. Invest. 52, 10-21.

Baars, A.J., Bakker, M.I., Baumann, R.A., Boon, P.E., Freijer, J.I., Hoogenboom, L.A.P., Hoogerbrugge, R., van Klaveren, J.D., Liem, A.K.D., Traag, W.A., de Vries, J., 2004. Dioxins, dioxin-like PCBs and non-dioxin-like PCBs in foodstuffs: occurrence and dietary intake in The Netherlands. Toxicol. Lett. 151, 51-61.

Baeyens, W., Leermakers, W., Elskens, W., Van Larebeke, N., De Bont, R., Vanderperren, H., Fontaine, A., Degroodt, J.M., Goeyens, L., Hanot, V., Windal, I., 2007. PCBs and PCDD/Fs in fish and fish products and their impact on the body burden in Belgium. Arch. Environ. Contam. Toxicol. 52, 563-571.

Bocio, A., Domingo, J.L., 2005. Daily intake of polychlorinated dibenzop-dioxins/polychlorinated dibenzofurans (PCDD/PCDFs) in foodstuffs consumed in Tarragona, Spain: a review of recent studies (2001-2003) on human PCDD/PCDF exposure through the diet. Environ. Res. 97, 1-9.

Darnerud, P.O., Atuma, S., Aune, M., Bjerselius, R., Glynn, A., Grawe, K.P., Becker, W., 2006. Dietary intake estimations of organohalogen contaminants (dioxins, $\mathrm{PCB}, \mathrm{PBDE}$ and chlorinated pesticides, e.g.
DDT) based on Swedish market basket data. Food Chem. Toxicol. 44, 1597-1606

De Bont, R., Elskens, M., Baeyens, W., Hens, H., van Larebeke, N., 2004. A survey of three PCB and dioxin contamination episodes: from contamination of food items to body burdens. In: Preedy, Victor R., Watson, Ronald R. (Eds.), Annual Reviews in Food and Nutrition: Toxic and Pathological Aspects. CRC Press, pp. 301-342.

European Commission, 2002. Official Journal of the European Communities. Commission Directive 2002/69/EC of 26 July 2002 laying down the sampling methods and the methods of analysis for the official control of dioxins and the determination of dioxin-like PCBs in foodstuffs.

Fattore, E., Fanelli, R., Turrini, A., di Domenico, A., 2006. Current dietary exposure to polychlorodibenzo- $p$-dioxins, polychlorodibenzofurans, and dioxin-like polychlorobiphenyls in Italy. Mol. Nutr. Food Res. 50, 915-921.

Focant, J.F., Eppe, G., Pirard, C., Massart, A.C., Andre, J.E., De Pauw, E., 2002. Levels and congener distributions of PCDDs, PCDFs and non-ortho PCBs in Belgian foodstuffs-assessment of dietary intake. Chemosphere 48, 167-179.

Fries, G.F., 1995. A review of the significance of animal food products as potential pathways of human exposures to dioxins. J. Anim. Sci. 73, $1639-1650$.

IARC, 1987. 2,3,7,8-Tetrachlorodibenzo-p-dioxins. IARC Monographs on The Evaluation Of Carcinogenic Risks to Humans, Supplement 7. In: Overall Evaluations of Carcinogenicity: An Updating of IARC Monographs, vols. 1-42. IARC, Lyon, France.

IARC, 1997. Polychlorinated dibenzo-para-dioxins and polychlorinated dibenzofurans. In: IARC Monographs On The Evaluation Of Carcinogenic Risks To Humans, vol. 69. IARC, Lyon, France.

Joung, K.E., Chung, Y.H., Sheen, Y.Y., 2007. DRE-CALUX bioassay in comparison with $\mathrm{HRGC/MS}$ for measurement of toxic equivalence in environmental samples. Sci. Total. Environ. 372, 657-667.

KAV-Practische School, 2003. Koken Voor Elke Dag, second ed. Kristelijke Arbeidersvrouwenbeweging, Brussels, Belgium.

Kiviranta, H., Ovaskainen, M.L., Vartiainen, T., 2004. Market basket study on dietary intake of PCDD/Fs, PCBs, and PBDEs in Finland. Environ. Int. 30, 923-932.

Krebs-Smith, S.M., Kott, P.S., Günther, P.M., 1989. Mean proportion and population proportion: two answers to the same question? J. Am. Diet. Assoc. 89, 671-676.

KVLV, 1999. Ons Kookboek, third ed. Katholiek Vormingswerk van Landelijke Vrouwen, Leuven, Belgium.

Lambe, J., 2002. The use of food consumption data in assessments of exposure to food chemicals including the application of probabilistic modelling. Proc. Nutr. Soc. 61, 11-18.

Liem, A.K., Fürst, P., Rappe, C., 2000. Exposure of populations to dioxins and related compounds. Food Addit. Contam. 17, 241-259.

Llobet, J.M., Domingo, J.L., Bocio, A., Casas, C., Teixido, A., Muller, L., 2003. Human exposure to dioxins through the diet in Catalonia, Spain: carcinogenic and non-carcinogenic risk. Chemosphere 50, 1193-1200.

Matthys, C., De Henauw, S., Devos, C., De Backer, G., 2003. Estimated energy intake, macronutrient intake and meal pattern of Flemish adolescents. Eur. J. Clin. Nutr. 57, 366-375.

Matthys, C., De Henauw, S., Bellemans, M., De Maeyer, M., De Backer, G., 2006. Sources of saturated fatty acids in Belgian adolescents' diet: implications for the development of food-based dietary guidelines. $\mathrm{Br}$. J. Nutr. 95, 546-554.

NEVO, 2001. NEVO Tabel: Nederlands Voedingsstoffenbestand. NEVO, Zeist.

NUBEL, 2004. Belgische Voedingsmiddelentabel, 4de ed. Ministerie van Volksgezondheid, Brussel.

Paalanen, L., Mannisto, S., Virtanen, M.J., Knekt, P., Rasanen, L., Montonen, J., Pietinen, P., 2006. Validity of a food frequency questionnaire varied by age and body mass index. J. Clin. Epidemiol. $59,994-1001$.

Parzefall, W., 2002. Risk assessment of dioxin contamination in human food. Food Chem. Toxicol. 40, 1185-1189. 
Pussemier, L., Mohimont, L., Huyghebaert, A., Goeyens, L., 2004. Enhanced levels of dioxins in eggs from free range hens; a fast evaluation approach. Talanta 63, 1273-1276.

Ruxton, C.H., Calder, P.C., Reed, S.C., Simpson, M.J., 2005. The impact of long-chain n-3 polyunsaturated fatty acids on human health. Nutr. Res. Rev. 18, 113-129.

Schoeters, G., Hoogenboom, R., 2006. Contamination of free-range chicken eggs with dioxins and dioxin-like polychlorinated biphenyls. Mol. Nutr. Food Res. 50, 908-914.

Schoeters, G., Goyvaerts, M.P., Ooms, D., Van Cleuvenbergen, R., 2004. The evaluation of dioxin and dioxin-like contaminants in selected food samples obtained from the Belgian market: comparison of TEQ measurements obtained through the CALUX bioassay with congener specific chemical analyses. Chemosphere 54, 1289 1297.

Scientific Advisory Committee on Nutrition, 2004. Advice On Fish Consumption: Benefits And Risks, ISBN 011243083 X, Crown copyright, Norwich, UK.

Scientific Committee on Food, 2001. Opinion of The Scientific Committee on Food on the Risk Assessment of Dioxins and Dioxin-like PCBs in Food, CS/CNTM/DIOXIN/20 final Brussels, Belgium.

Sioen, I.A., Pynaert, I., Matthys, C., De Backer, G., Van Camp, J., De Henauw, S., 2006. Dietary intakes and food sources of fatty acids for Belgian women, focused on $n-6$ and $n-3$ polyunsaturated fatty acids. Lipids 41, 415-422.

Van den Berg, M., Birnbaum, L., Bosveld, A.C., Brunström, B., Cook, P., Feeley, M., Giesy, J.P., Hanberg, A., Hasegawa, R., Kennedy, S.W., Kubiak, T., Larsen, J.C., van Leeuwen, F., Liem, A.K., Nolt, C., Peterson, R.E., Poellinger, L., Safe, S., Schrenk, D., Tillitt, D., Tysklind, M., Younes, M., Waern, F., Zacharewski, T., 1998. Toxic equivalency factors (TEFs) for PCBs, PCDDs, PCDFs for humans and wildlife. Environ. Health Persp. 106, 775-792.

Van den Berg, M., Birnbaum, L.S., Denison, M., De Vito, M., Farland, W., Feeley, M., Fiedler, H., Hakansson, H., Hanberg, A., Haws, L., Rose, M., Safe, S., Schrenk, D., Tohyama, C., Tritscher, A., Tuomisto, J., Tysklind, M., Walker, N., Peterson, R.E., 2006. The 2005 World Health Organization reevaluation of human and mammalian toxic equivalency factors for dioxins and dioxin-like compounds. Toxicol. Sci. 93, 223-241. van Dooren-Flipsen, M.M., van Klaveren, J.D., 1998 ANI-voedselfrequentievragenlijst: Ontwikkeling Vragenlijst Naar De Inname Van Vetoplosbare Residuen En Contaminanten, Bilthoven, The Nederlands. RIVM Report No. 98.004.

Van Overmeire, I., Goeyens, L., Beernaert, H., Srebnik, S., De Poorter, G., Baeyens, W., Clark, G., Chu, M., Chu, A., Chu, D., Morris, R., Brown, D., 2000. A comparative study of GC-HRMS and CALUX ${ }^{\mathrm{TM}}$ TEQ determinantions in food samples by the Belgian Federal Ministries of Public Health and Agriculture. Organohalo. Compd. 45, 196-199.

Van Overmeire, I., Van Loco, J., Roos, P., Carbonnelle, S., Goeyens, L., 2004. Interpretation of CALUX results in view of the EU maximal TEQ level in milk. Talanta 63, 1241-1247.

Vanderperren, H., Van Wouwe, N., Behets, S., Windal, I., Van Overmeire, I., Fontaine, A., 2004. TEQ-value determinations of animal feed; emphasis on the CALUX bioassay validation. Talanta 63, 1277-1280.

Vrijens, B., De Henauw, S., Dewettinck, K., Talloen, W., Goeyens, L., De Backer, G., Willems, J.L., 2002. Probabilistic intake assessment and body burden estimation of dioxin-like substances in background conditions and during a short food contamination episode. Food Addit. Contam. 19, 687-700.

WHO, 1989. In: Polychlorinated Dibenzo-para-dioxins and Dibenzofurans, vol. 88. World Health Organisation, Geneva, Switzerland.

WHO, 1993, second ed. In: Polychlorinated Biphenyls and Terphenyls, vol. 140 World Health Organisation, Geneva, Switzerland.

WHO, 1995. In: Physical Status: The Use and Interpretation of Anthropomethry, vol. 854. World Health Organisation, Geneva, Switzerland.

WHO, 2004. Global Strategy on Diet Physical Activity and Health Resolution of The Fifty Seventh World Health Assembly. WHO, Geneva, Switserland.

WHO-ECEH-IPCS, 2000. Consultation on assessment of the health risks of dioxins; re-evaluation of the tolerable daily intake (TDI): executive summary. Food Addit. Contam. 17, 223-240.

Willett, W.C., 1994. Future directions in the development of foodfrequency questionnaires. Am. J. Clin. Nutr. 59, 171S-174S.

Willett, W.C., 1998. Nutritional Epidemiology, second ed. Oxford University Press, New York.

Willett, W.C., 2000. Will high-carbohydrate/low-fat diets reduce the risk of coronary heart disease? Proc. Soc. Exp. Biol. Med. 225, 187-190. 